\title{
Correspondence
}

Cerebrovascular Diseases

Published online: December 21, 2010

Cerebrovasc Dis 2011;31:207-208

DOI: $\underline{10.1159 / 000321906}$

\section{Hyperdense Middle Cerebral Artery Sign and Stroke Outcomes after Intravenous Thrombolysis}

Vijay K. Sharma, N. Venketasubramanian, Hock Luen Teoh, Bernard P.L. Chan

Division of Neurology, National University Hospital System,

Singapore, Singapore

We read with interest the study by Overbeek et al. [1] regarding the relationship between disappearing hyperdense middle cerebral artery sign (HMCAS) and striatocapsular infarcts on follow-up CT scans in acute ischemic stroke (AIS) patients treated with intravenous thrombolysis. This paper raises some important issues.

Although a significant number of AIS patients recover with optimal care and timely administered thrombolysis $[2,3]$, the rates and the extent of recovery remain highly variable [4]. Considering the scarce and costly resources, early identification of reliable predictors for good outcomes is important for planning interventions and rehabilitation strategies. Although the National Institute of Health Stroke Scale score, age, gender and infarct volumes are established predictors of good outcomes [5-7], the disability score at day 7 might be a better predictor of long-term outcomes [8], as it excludes the neurological fluctuations during the first few days of AIS.

HMCAS is believed to represent the presence of a thrombus, associated with severe neurological deficits and poor clinical outcome [9]. However, its interpretation requires some important considerations. First, HMCAS on the initial scan can reliably predict the possible poor clinical outcome only in patients managed conservatively. In thrombolyzed patients, disappearance of HMCAS on the follow-up scan represents thrombus dissolution or fragmentation. We agree that some MCA occlusions may not recanalize completely, especially its deeper branches, and result in striatocapsular infarcts. However, such cases often show peripheral infarcts due to distal embolization of clot fragments

Fig. 1. Case 1 presented with acute left-sided weakness of $2 \mathrm{~h}$ duration. Unenhanced CT scan of the brain performed before thrombolysis showed HMCAS on the right side (a). HMCAS disappeared on the CT scan repeated on day 2 (b). Scattered peripheral hypodensities were noted in the right MCA territory (c). Although the HMCAS disappeared, the right MCA remained occluded on the CT angiography on day 2 (d). Case 2 presented with acute right-sided weakness of 90-min duration. Pretreatment unenhanced CT scan showed left HMCAS (e). Follow-up CT scan on day 2 showed persistence of left HMCAS (f) despite significant clinical improvement. Left cortical hypodensities represented the final infarcts (g). Although the left HMCAS persisted on the follow-up scan, CT angiography revealed complete recanlization of the left MCA (h).

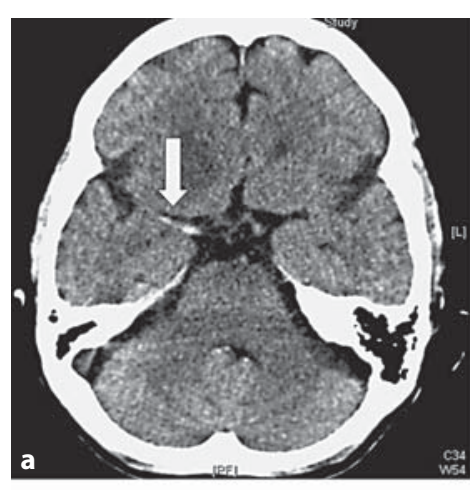

Case 1
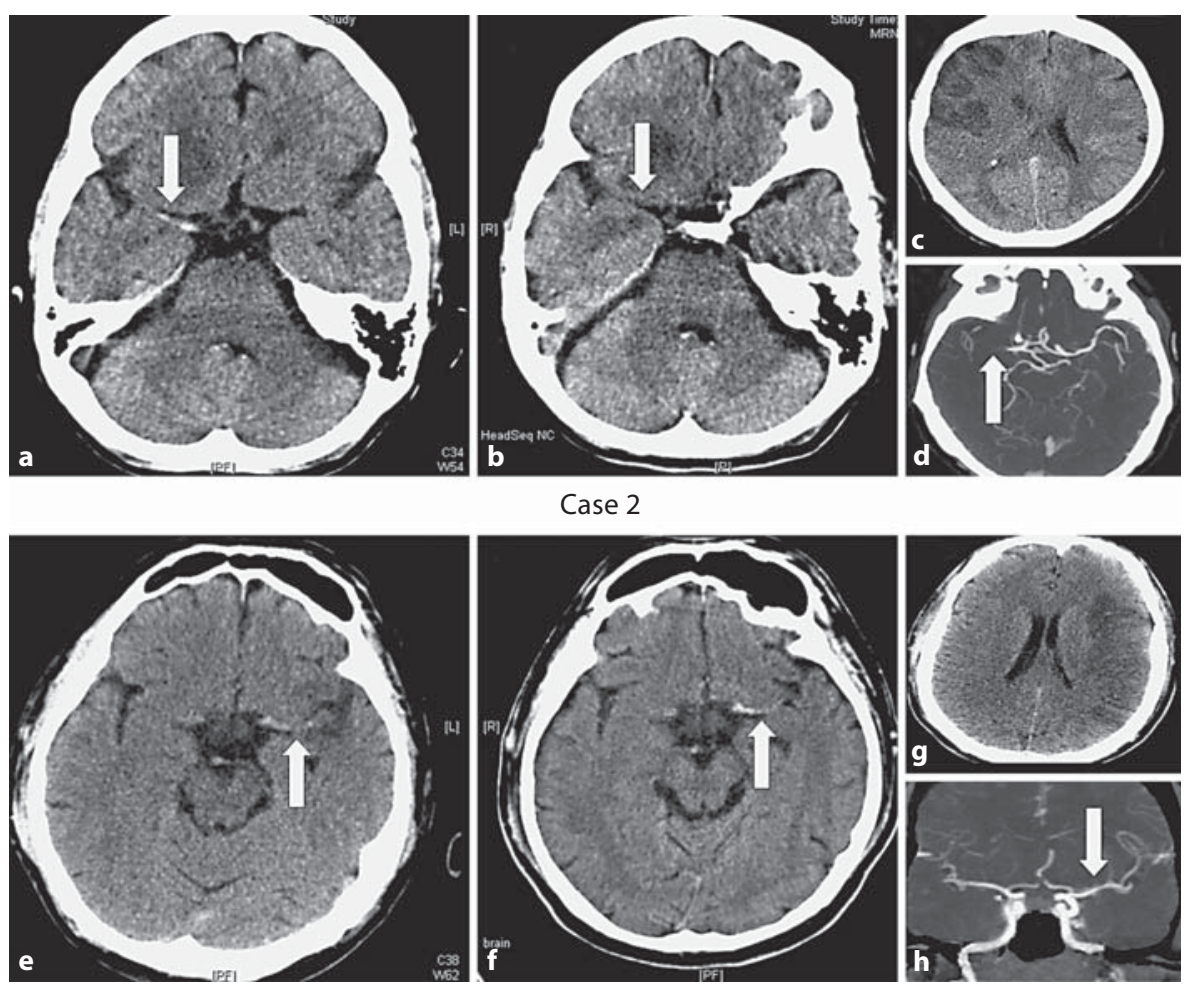

Case 2
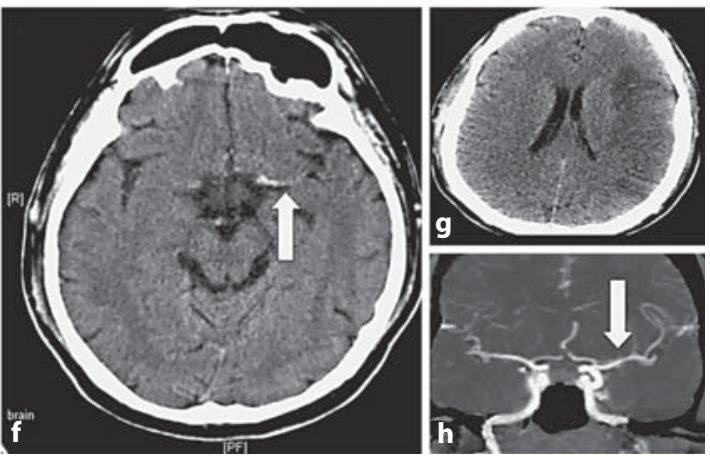

\section{KARGER}

Fax +41613061234 E-Mail karger@karger.ch www.karger.com
(2) 2010 S. Karger AG, Basel

1015-9770/11/0312-0207\$38.00/0 
(fig. 1, case 1). On the contrary, thrombolysis-induced complete arterial recanalization might be too late to prevent the tissue damage despite clearing the HMCAS. Second, HMCAS on the followup scan carries an important prognostic significance, raising the question of which is more relevant - its disappearance or persistence? While its disappearance may not represent complete recanalization (fig. 1, case 1), reliable assessments and outcome predictions are still possible from other imaging findings (final infarct size, intracranial hemorrhage and cerebral edema). Third, in patients who develop cerebral infarcts adjacent to the affected artery, the resultant hypodensity produces an enhanced grayscale gradient, producing a 'pseudo-hyperdense' MCA. Finally, HMCAS on the follow-up scan should be interpreted in reference to the pretreatment CT scan. While HMCAS on the pretreatment scan represents an underlying thrombus, it may persist on the follow-up scan despite proven arterial recanalization (fig. 1, case 2). Although difficult to substantiate, a persistent HMCAS despite a patent artery on the post-thrombolysis scans could represent injury/inflammation of the arterial wall. Our tertiary care center runs an active thrombolysis program [10], and CT angiography is performed in most of the patients, both before thrombolysis as well as on day 2. In our experience, disappearance of HMCAS on the follow-up scan may not always result in good outcome; its persistence is mostly associated with poor outcome.

In conclusion, we propose that instead of looking for the disappearance of HMCAS, it might be wiser to look for its persistence on the follow-up scan, and other imaging findings should be taken into account for predicting long-term outcomes.

\section{References}

1 van Overbeek EC, Knottnerus ILH, van Oostenbrugge RJ: Disappearing hyperdense middle cerebral artery sign is associated with striatocapsular infarcts on follow-up CT in stroke patients treated with intravenous thrombolysis. Cerebrovasc Dis 2010;30:285-289.

2 The National Institute of Disorders and Stroke rt-PA Stroke Study Group: Tissue plasminogen activator for acute ischemic stroke. N Engl J Med 1995;333:1581-1587.
- 3 Wahlgren N, Ahmed N, Dávalos A, Ford GA, Grond M, Hacke W, Hennerici MG, Kaste M, Kuelkens S, Larrue V, Lees KR, Roine RO, Soinne L, Toni D, Vanhooren G, SITS-MOST investigators: Thrombolysis with alteplase for acute ischaemic stroke in the Safe Implementation of Thrombolysis in Stroke Monitoring Study (SITS-MOST): an observational study. Lancet 2007;369:275-282.

-4 Jorgensen HS, Nakayama H, Raaschou HO, Olsen TS: Stroke: neurologic and functional recovery. The Copenhagen Stroke Study. Phys Med Rehabil Clin N Am 1999;10:887-906.

-5 Brott T, Adams HP Jr, Olinger CP, Marler JR, Barsan WG, Biller J, Spilker J, Holleran R, Eberle R, Hertzberg V, et al: Measurements of acute cerebral infarction: a clinical examination scale. Stroke 1989;20:864870 .

6 Weimar C, Ziegler A, Konig IR, Diener HC: Predicting functional outcome and survival after acute ischemic stroke. J Neurol 2002;249:888895.

$\checkmark 7$ Adams HP Jr, Davis PH, Leira EC, Chang KC, Bendixen BH, Clarke WR, Woolson RF, Hansen MD: Baseline NIH Stroke Scale score strongly predicts outcome after stroke: a report of the Trial of Org 10172 in Acute Stroke Treatment (TOAST). Neurology 1999;53:126-131.

8 Hallevi H, Albright KC, Martin-Schild SB, Barreto AD, Morales MM, Bornstein N, Ifejika NL, Shuaib A, Grotta JC, Savitz SI, on behalf of the VISTA investigators: Recovery after ischemic stroke: criteria for good outcome by level of disability at day 7. Cerebrovasc Dis 2009;28:341348.

-9 Somford DM, Nederkoorn PJ, Rutgers DR, Kapelle LJ, Mali WPTM, van der Grond J: Proximal and distal hyperattenuating middle cerebral artery signs at CT: different prognostic implications. Radiology 2002; 223:667-671.

10 Sharma VK, Tsivgoulis G, Tan JH, Wong LY, Ong BK, Chan BP, Teoh HL: Feasibility and safety of intravenous thrombolysis in multiethnic Asian stroke patients in Singapore. J Stroke Cerebrovasc Dis 2010, Epub ahead of print.

Dr. Vijay Sharma

Division of Neurology, Department of Medicine

National University Hospital System

Singapore 119074 (Singapore)

Tel. +65 6772 2516, Fax +65 6872 3566, E-Mail drvijay@ singnet.com.sg 